\title{
Changes in family structure in early childhood in the Millennium Cohort Study
}

\author{
Lidia Panico, Mel Bartley ${ }^{1}$, Yvonne Kelly ${ }^{1}$, Anne McMunn ${ }^{1}$ and Amanda Sacker ${ }^{2}$ \\ 1 Department of Epidemiology and Public Health, University College London \\ 2 Institute for Social and Economic Research, University of Essex
}

\begin{abstract}
This article develops a typology of family change over the first five years of children's lives using data from the Millennium Cohort Study. It examines the changes over time of parental living arrangements and describes a range of social, economic and well-being indicators. It shows that nearly three quarters of this sample of young children have not experienced changes in family structures. The most advantaged group appears to be children living with continuously married parents, followed by those who live with cohabiting parents who marry. Children who experienced changes in family structure are a diverse group. Coupled parents who separate suffer the largest drop in income over five years. Lone parents who partner gain the most income. However, their incomes are still much lower than continuously partnered parents. This article suggests that using static or overly simplified measures of family structure hides important variations in the experiences of children.
\end{abstract}




\section{Contents}

Changes in family structure in early childhood in the Millennium Cohort Study ........78

Abstract.

Introduction

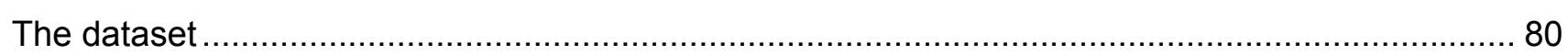

Family structure: a cross-sectional snapshot and a longitudinal approach.................................. 81

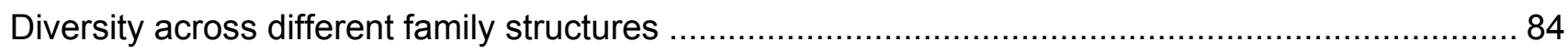

Conclusions ……

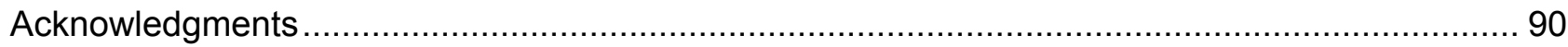

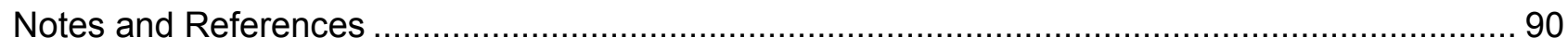




\section{Introduction}

The traditional family structure with a married couple and their co-resident children is declining, largely due to an increase in the number of households containing cohabiting or lone parents. There has been much debate about these large societal changes, especially focusing on the consequences for children and the wider community. A number of studies have shown that children growing up with two continuously married parents do better than children in lone parent families on a range of cognitive, emotional and developmental outcomes, both in childhood and adulthood (reviews of the literature include Amato and Keith 1991; Aquilino 1996; Cherlin, ChaseLansdale et al. 1998; Amato 2001; Amato 2005). We do not know as much about cohabitees and their children. However, children of cohabiting parents appear to have poorer outcomes than those of married parents. For example, they are more likely to experience behavioural and emotional problems and have poorer school engagement (Brown 2004).

While the diversity, instability and inequalities of different family settings are widely recognised in public discourse, academic literature often focuses on cross-sectional data which cannot fully capture the intrinsically dynamic quality of family life. Many studies implicitly assume that children's family environments are fairly static over their childhood, or that, at most, allowance is only needed for a single event such as parental divorce or remarriage (Kiernan, 1997). However, children are now likely to experience a variety of family structures before adulthood. In the US, Aquilino found that only one in five children born to a single mother spent their entire childhood in a lone parent household (Aquilino 1996). Such longitudinal patterns of family change and stability in early childhood have yet to be documented in the UK population, although some work exists for older children (Clarke and Joshi, 2003). Furthermore, few studies have access to a dataset rich enough to be able to distinguish between several different typologies of family change. Longitudinal UK data is potentially very important in describing the changing family environment of young children and in understanding the relationships between family structure and outcomes for family members.

This article describes the family environment that young children experience during the first five years of their lives using data from the Millennium Cohort Study (MCS). The MCS is a recent, longitudinal and nationally representative cohort study that follows the lives of children born in the UK in a period between 2000 and 2002. Home interviews have been carried out with the child's main carer, usually the mother. This article focuses on data collected when the child was aged approximately nine months, three and five years. This article will identify several typologies of family change, ranging from stable households to households which experience more than one transition in family structure. A wide range of literature has shown that changes in family structures are associated with changes in income and the wellbeing of family members, particularly those affected by family conflict and stress such as maternal mental health (Aassve et al, 2007; Barrett, 2000; Richards et al, 1997). Therefore, to describe these diverse groups, their socio-economic characteristics are outlined, along with some markers of wellbeing such as maternal depression and the child's birthweight.

\section{The dataset}

The MCS includes 18,818 children born in the UK over the period 2000-2002. In England and Wales, cohort members were born in a 12 month period from September 2000. In Scotland and 
Northern Ireland cohort members were born over a slightly longer 13.5 month period from November 2000 to make up for a shortfall in sample numbers.

The sample has a probability design and is clustered at the electoral ward level. The sampled wards over-represent areas with a high ethnic minority density, areas with high levels of child poverty, and the three smaller UK countries. A ward was considered as having a high proportion of ethnic minority population if at the 1991 UK Census over 30 per cent of the population was classed as Black or Asian. ${ }^{1}$ A ward was considered disadvantaged if it was not classed as a ward with a high proportion of ethnic minority population and was in the poorest 25 per cent wards based on the Child Poverty Index (Dex and Joshi 2005).

Four sweeps of data collection have been carried out: when cohort members were aged about nine months, three, five and seven years. This article will consider the first three sweeps. Survey weights have been calculated, both to correct for cohort members having unequal probabilities of selection into the study due to the stratified clustered sample design, as well as to take into account the loss of certain households between sweeps and unit non-response (that is, missing answers to certain questions) (Plewis 2007). The analyses presented in this article use the appropriate weights.

The study mainly consists of interviews with the main carer. This was the mother in 98 per cent of cases. The MCS contains detailed health measures for children, as well as measurements of family circumstances, and the socio-economic, health and health behaviour characteristics of members of the household. Information is collected on the number of parents in the household, their relationship, and any changes to that relationship over the study period. Full details on the study, including the sampling strategy, weights and questionnaires are available in the documentation attached to the data deposited with the Data Archive at Essex University.

\section{Family structure: a cross-sectional snapshot and a longitudinal approach}

In the MCS, at sweep 1, when the children were aged approximately nine months, nearly 60 per cent lived with two married parents, 23 per cent with two cohabiting parents and 17 per cent with one parent. In the MCS, retrospective questions were also asked about the parents' relationship at the birth of the child. Table 1 shows that there is little difference between family structure at birth and nine months.

\section{Table 1 Distribution of family structures at different ages,} percentages

\begin{tabular}{lrrrr}
\hline & At birth & 9 months & 3 yrs & 5 yrs \\
\hline Married & & & & \\
Cohabiting & 57.2 & 58.9 & 61.8 & 61.6 \\
Lone parent & 23.5 & 23.4 & 17.1 & 18.2 \\
Unweighted sample & 18.8 & 17.5 & 20.1 & 19.9 \\
\hline
\end{tabular}


Our results are similar to birth registration data: about 60 per cent of all live births registered in England and Wales in 2000 were registered to married parents, 20 per cent to unmarried parents living together and 20 per cent to a sole parent (ONS, 2001).

Table 1 also presents consecutive cross-sectional snapshots of family structure at nine months, three and five years.

Table 2 looks at the data longitudinally. The shaded rows show the proportion of families who did not experience changes in family structure over the first five years of the cohort child's life. Children who were born to married parents had the highest chance of still being in the same family structure at age five (91 per cent compared with 54 per cent of those born to cohabiting parents and 57 per cent of those born to lone parents). The proportions of cohabitees at birth and lone parents at birth who experienced a change in family structure by age five are similar to one another. At nine months the differences between those who were cohabiting when the child was born and those who were lone parents when the child was born are still observable (nearly 86 per cent of cohabitees were still in the same family structure nine months after birth, compared with 75 per cent of lone parents). By age three these differences have diminished and by age five, about 46 per cent of children born to cohabiting parents and 43 per cent of children born to lone parents had experienced a change in family structure.

Just looking at changes in family structure may misrepresent the picture for cohabiting parents. In fact, as shown in Table 2, over half of those who were no longer cohabiting by age five had married; all had married their cohabiting partner except for 12 couples. Therefore, the rate of partnership dissolution is much lower at 19 per cent.

\section{Table $2 \quad$ Change and stability in family structures over time, compositional change, percentages}

\begin{tabular}{lccr}
\hline & Relationship status at: \\
\hline & 9 months & $\mathbf{3}$ yrs & $\mathbf{5}$ yrs \\
\hline Married at birth & & & \\
Married (no change) & 98.5 & 93.4 & 90.8 \\
Cohabiting & 0.2 & 0.8 & 1.7 \\
Lone parent & 1.2 & 4.8 & 7.2 \\
Cohabiting at birth & & & \\
Married & 7.1 & 27.9 & 27.1 \\
Cohabiting (no change) & 85.7 & 56.1 & 53.7 \\
Lone parent & 6.6 & 15.2 & 18.7 \\
Not living with father at birth & & & \\
Married & 5.6 & 13.1 & 14.7 \\
Cohabiting & 17.5 & 25.9 & 27.6 \\
Lone parent (no change) & 75.3 & 60.0 & 57.5 \\
Unweighted sample (cases with complete longitudinal data) & 13,234 & \\
\hline Note: & \multicolumn{3}{l}{} \\
Shaded rows represent groups who did not experience a change in family structure.
\end{tabular}


Table 2 also shows that the majority of married couples who separated before their child's fifth birthday became lone parents. Lone parent households that had become couple households by age five tended to be cohabiting rather than married.

The MCS collects information on all the resident members of the households in a 'household grid', providing information the year in which each household member entered and left, if applicable. This allows us to explore family structure during the periods of time in between sweeps. Table 3 shows the proportion of children who experience a change in parent or parental figure (for example, a new partner moving in or out of the household). This includes both households who gained a new parent or parental figure and those who lost one. The information in Table 3 is useful as it helps fill the gaps on what happens between data collection sweeps and provides information on partner change which is not necessarily captured by family structure. For example, brief periods of lone parenthood between sweeps or cohabitation with two different partners may have been missed in the data presented above.

Table 3 confirms that children living with cohabiting or lone parents were most likely to experience a change in parents or parental figures. Encouragingly, the figures that emerge from using the household grid are not very different than from those presented above. Until three years of age, children born into cohabiting households were most likely to see a change in parents or parental figures, with 17 per cent having experienced such a change by age three. By age five, children born to lone parents were slightly more likely than those born into cohabiting households to experience a change in parents or parental figures (24 per cent versus 21 per cent). By contrast, married couple households had lower rates of change throughout, reaching just under seven per cent by age five.

\section{Table 3 Households who experience a change in parents or parental figure}

\begin{tabular}{lrrr}
\hline & \multicolumn{3}{c}{ Percentage with change in parents by: } \\
\hline Relationship status at birth & $\mathbf{9}$ months & $\mathbf{3}$ yrs & $\mathbf{5}$ yrs \\
\hline Married & & & \\
Cohabiting & 1.0 & 4.5 & 6.7 \\
Lone parent & 6.6 & 17.0 & 21.0 \\
Unweighted sample & 5.1 & 11.3 & 24.2 \\
\hline
\end{tabular}

To summarise the different experiences of family change and to be able to describe these groups, we created a typology of family change over the first five years of the children's life (see Table 4). The first three groups ('always married', 'always cohabiting' and 'always lone parents') are stable groups that did not show changes in family structure from birth and across the three sweeps of data. They make up nearly 73 per cent of the sample. A further 20 per cent of the sample is made up of families who experienced one change, for example, couples who separate. The largest group within this part of the sample was cohabitees who married; they made up about six per cent of the total and largely consisted of marriages between the same two parents. Two groups of couples (married and cohabitees) who became lone parents constituted eight per cent of the sample. Lone parents who get married or moved in with a partner made up six per cent of the sample. The remainder of the sample was composed of households that experienced more than one change in family structure. This group could not be further stratified because of small sample sizes. 


\section{Table $4 \quad$ Typologies of family change over the first 5 years of life}

\begin{tabular}{lrr}
\hline & Per cent & $\begin{array}{r}\text { Sample size } \\
\text { (unweighted) }\end{array}$ \\
\hline No changes & & \\
Always married & 55.0 & 7,148 \\
Always cohabiting & 10.8 & 1,398 \\
Always lone parent & 7.0 & 908 \\
Total & $\mathbf{7 2 . 8}$ & $\mathbf{9 , 4 5 4}$ \\
& & \\
One transition & & 788 \\
Cohabiting to married & 6.1 & 556 \\
Married to lone parent & 4.3 & 474 \\
Cohabiting to lone parent & 3.6 & 506 \\
Lone parent to cohabiting & 3.9 & 240 \\
Lone parent to married & 1.9 & $\mathbf{2 , 5 6 4}$ \\
Total & $\mathbf{1 9 . 7}$ & 990 \\
More than one transition & 7.5 & 13,008 \\
\hline Unweighted sample & & \\
\hline
\end{tabular}

\section{Diversity across different family structures}

Do these different typologies of family change over the first five years of life matter? To describe these groups, the next tables show a number of social, economic, demographic and wellbeing indicators. To begin, Table 5 describes the groups outlined above in terms of their socio-economic characteristics. The analyses confirm that, when limited to a sample of parents with young children, some familiar patterns are observed: continuously married parents are the highest earners, while continuously lone parents have the lowest income. Equivalised incomes ${ }^{2}$ allow us to compare across different households as they take into account the number of adults and children and their ages.

At sweep 1, when the cohort children were on average nine months old, equivalised parental income for households who stayed married throughout the five years was $£ 436$ per week. Parents who remained in a cohabiting relationship earned $£ 340$. Those who remained lone parents earned $£ 141$.Therefore, even after taking account of different sizes and structures of households, there was nearly $£ 300$ difference in equivalised weekly incomes between those who remained married and those who remained lone parents.

The 'always lone parent' group also had lower incomes than those groups that experienced family changes. Cohabitees who married earned slightly more than those who stayed in an unmarried cohabiting relationship ( $£ 371$ versus $£ 340$ per week), although this difference was not statistically significant. At nine months, coupled parents who became lone parents earned about $£ 100$ per week less than their equivalents who remained as couples. Therefore, those whose relationship breaks up appear to be already poorer before the actual separation occurs. In a similar vein, lone parents who would go on to partner already earned more than those who would remain lone parents, although their earnings are still much less than for the continuously partnered groups.

It is difficult to comment upon households who experience more than one transition as they are a heterogeneous group. As a result, they will not be discussed at length in this article. 
The proportion of households where the highest parental occupational level was a routine or a semi-routine job (see endnotes ${ }^{3}$ for a description of these categories) at nine months show a similar pattern. Among the stable groups, the married group was least likely to be in a less advantaged occupation, followed by cohabitees and lone parents. Across the groups that experienced one transition, the cohabitees who married were less likely to be in routine occupations (and do slightly better in this respect than the cohabitees who do not marry); the coupled groups that became lone parents were more likely to be in routine occupations than their consistently coupled counterparts; and the lone parents who married tended to be in more advantaged occupations than the 'always lone parent', although still showing disadvantage compared with the always partnered groups. In contrast to the income data, lone parents who went on to cohabit were just as likely to be in routine or semi-routine occupations as were lone parents who did not partner, although within these broad occupational groups their income was somewhat higher.

The penultimate column in Table 5 shows the proportion of households where no parent had any educational qualifications when the cohort child was nine months old. This pattern is again similar to the proportion outlined above, with a marked disadvantage for lone parent households. This could be partially due to their younger age profile (see below).

\section{Table $5 \quad$ Household characteristics at 9 months, by typology of family change from birth to age 5}

\begin{tabular}{|c|c|c|c|c|c|}
\hline & $\begin{array}{r}\mathrm{Me} \\
\text { equivalise } \\
(95 \%\end{array}$ & $\begin{array}{r}\text { ean weekly } \\
\text { d parental } \\
\text { ncome }(£) \\
\text { confidence } \\
\text { interval) } \\
\end{array}$ & $\begin{array}{l}\text { Households in } \\
\text { semi- \& routine } \\
\text { occupations, } \\
\text { percentage }\end{array}$ & $\begin{array}{r}\text { Households } \\
\text { with no } \\
\text { educational } \\
\text { qualifications, } \\
\text { percentage } \\
\end{array}$ & $\begin{array}{r}\text { Maternal age } \\
\text { at birth of } \\
\text { cohort member }\end{array}$ \\
\hline Always married & 436 & $(414-459)$ & 29.9 & 2.8 & 31.1 \\
\hline Always cohabiting & 340 & (319-360) & 49.3 & 3.9 & 28.3 \\
\hline Always lone parent & 141 & $(135-148)$ & 52.6 & 26.0 & 25.5 \\
\hline Cohabiting to married & 371 & $(351-392)$ & 47.5 & 2.9 & 28.0 \\
\hline Married to lone parent & 345 & (320-371) & 47.4 & 5.2 & 29.5 \\
\hline Cohabiting to lone parent & 250 & $(228-271)$ & 59.1 & 9.4 & 25.8 \\
\hline Lone parent to cohabiting & 162 & $(150-178)$ & 58.7 & 19.8 & 24.2 \\
\hline Lone parent to married & 209 & $(169-250)$ & 49.7 & 22.4 & 27.3 \\
\hline More than one transition & 242 & $(227-257)$ & 58.1 & 10.5 & 26.3 \\
\hline$p$-value & & & $<0.001$ & $<0.001$ & $<0.001$ \\
\hline Unweighted sample & & 11,999 & 5,713 & 1,140 & 13,008 \\
\hline
\end{tabular}

The final column of Table 5 shows average maternal age at birth of the cohort child. Couples who remained married throughout the study contained older mothers than other groups (31 years at the birth of the cohort child). Among the stable groups, the cohabitees were younger than the married (28 years) and both groups were older than the lone parents (25.5 years). Cohabitees who married were of the same age as the always cohabiting mothers, while married and cohabiting mothers who became lone parents were younger than their constantly coupled peers. Lone parents who went on to cohabit were on average a year younger than lone parents who did not partner, while 
lone parents who got married were on average nearly two years older than their 'always lone parents' counterparts.

The next part of the analysis looks at changes in economic circumstances over the first five years of life according to the typologies of family change.

To look at the longitudinal experience of poverty we constructed a persistent poverty score, flagging up when mean equivalised parental income was below 60 per cent of the median at each sweep (Table 6). Describing the sample in this manner broadly confirms the pattern depicted above, while emphasising the persistent poverty of some groups as well as the dynamic household circumstances of others. While about 20 per cent of 'always married' households experienced poverty at least at one sweep, poverty was likely to be a transient state (only four per cent were 'always poor'). In contrast, 60 per cent of 'always lone parent' households were poor at every sweep and only 10 per cent never experienced poverty compared with 81 per cent of married households and 65 per cent of cohabiting households who never experienced poverty. The 'always cohabiting' appeared to be slightly worse off than the 'always married' (35 per cent of cohabiting households experienced poverty at some stage). However, only 8.5 per cent of 'always cohabiting' households were poor at every sweep. Therefore, having two partners in the household appears to provide a safety net against persistent income poverty.

Among the groups that had experienced at least one change, cohabitees who married did particularly well, with 72 per cent of them never experiencing poverty. This is better than the 'always cohabiting' but still not as high as the 'always married' group. Of the separating couples, over 50 per cent of married parents who became lone parents and 75 per cent of cohabitees who separate experienced poverty at least once. This is much higher than their stable-partnered counterparts. Lone parents who went on to marry or cohabit had smaller chances of experiencing poverty than their 'always lone parent' counterparts (70 per cent and 80 per cent respectively experienced poverty, compared with the 90 per cent of 'always lone parent'), but these proportions are still much higher than their always coupled peers.

The final column in Table 6 shows the difference in mean equivalised weekly income between nine months and five years. Those who gained the most income were lone parents who married, followed by lone parents who went on to cohabit, gaining $£ 135$ and $£ 110$ per week respectively. It is important to note that their initial incomes at nine months were some of the lowest across all groups and, in spite of their increased income, these two groups did not catch up with the incomes of those who were continuously partnered. Those who lost the most income were married parents who became lone parents. On average this group suffered a decrease in income of $£ 74$ per week. Cohabitees who became lone parents experienced a smaller loss of income of about $£ 26$ per week. After five years, households with continuously lone parents still had the lowest income of all groups. These figures are equivalised for the number of people in the household, accounting for changes in the number and composition of household members. 


\section{Table $6 \quad$ Longitudinal economic characteristics between 9 months} and 5 yrs, by typology of family change from birth to age 5

\begin{tabular}{|c|c|c|c|c|c|}
\hline & \multicolumn{4}{|c|}{ Persistent poverty status ${ }^{*}$, percentage } & \multirow{2}{*}{$\begin{array}{r}\text { Change in } \\
\text { parental income } \\
\text { between } 9 \text { months } \\
\text { and } 5 \text { yrs }(£)\end{array}$} \\
\hline & $\begin{array}{r}\text { Never } \\
\text { poor }\end{array}$ & $\begin{array}{r}\text { Poor at one } \\
\text { sweep }\end{array}$ & $\begin{array}{r}\text { Poor at } \\
\text { two } \\
\text { sweeps }\end{array}$ & $\begin{array}{r}\text { Always } \\
\text { poor }\end{array}$ & \\
\hline Always married & 80.6 & 10.8 & 4.5 & 4.1 & +51 \\
\hline Always cohabiting & 64.9 & 17.3 & 9.4 & 8.5 & +49 \\
\hline Always lone parent & 9.7 & 8.4 & 22.8 & 59.1 & +44 \\
\hline Cohabiting to married & 72.2 & 17.1 & 6.3 & 4.4 & +51 \\
\hline Married to lone parent & 46.7 & 22.6 & 15.6 & 15.2 & -74 \\
\hline Cohabiting to lone parent & 24.5 & 21.0 & 27.0 & 27.5 & -26 \\
\hline Lone parent to cohabiting & 20.1 & 21.6 & 25.1 & 33.2 & +110 \\
\hline Lone parent to married & 29.4 & 27.2 & 23.1 & 20.4 & +135 \\
\hline More than one transition & 32.9 & 23.0 & 19.0 & 25.2 & +53 \\
\hline p-value & & & & $<0.001$ & \\
\hline Unweighted sample & 5,652 & 1,418 & 1,089 & 1,523 & 10,932 \\
\hline
\end{tabular}

*Note:

Poverty is classed as earning below 60 per cent of the median of the equivalised incomes at each sweep.

To continue our description of families that experience changes in family structure, we now look at a number of indicators of child and parental wellbeing that previous literature has linked to experiencing family conflict and stress, as well as to changes in family structure (Table 7).

Table $7 \quad$ Child and parental well-being at 9 months, by typology of family change from birth to age 5

\begin{tabular}{lrrrr}
\hline & $\begin{array}{r}\text { Child's birthweight, } \\
\text { grams }\end{array}$ & $\begin{array}{r}\text { Either parent } \\
\text { smokes, } \\
\text { percentage }\end{array}$ & $\begin{array}{r}\text { Mother } \\
\text { depressed, } \\
\text { percentage }\end{array}$ \\
\hline Always married & 3,412 & $(3,394-3,431)$ & 29.6 & 1.7 \\
Always cohabiting & 3,336 & $(3,298-3,373)$ & 57.6 & 2.6 \\
Always lone parent & 3,220 & $(3,169-3,271)$ & 59.1 & 7.7 \\
Cohabiting to married & 3,392 & $(3,342-3,443)$ & 51.6 & 2.3 \\
Married to lone parent & 3,261 & $(3,136-3,385)$ & 46.8 & 4.7 \\
Cohabiting to lone parent & 3,258 & $(3,186-3,331)$ & 65.8 & 5.8 \\
Lone parent to cohabiting & 3,308 & $(3,250-3,366)$ & 64.5 & 7.6 \\
Lone parent to married & 3,221 & $(3,129-3,312)$ & 37.1 & 6.7 \\
More than one transition & 3,305 & $(3,247-3,363)$ & 60.2 & 6.5 \\
p-value & & & $<0.001$ & 0.001 \\
Unweighted sample & & & 5,546 & 398 \\
\hline
\end{tabular}

As a marker of child health, we look at birthweight. Birthweight was highest in the continuously married group and for cohabitees who married. Relatively low birthweights were observed across the continuously lone parent group, the coupled parents who separated and lone parents who married. Maternal mental health is examined by looking at maternal depression measured using the Malaise Inventory (Rutter et al, 1970) when the child was aged nine months. Maternal 
depression was especially high among lone parents and lone parents who married. Cohabitees who married experienced slightly lower depression rates than continuously cohabiting parents. Coupled parents who separated had over twice the rates of depression of their continuously coupled peers, even when the child was aged nine months. Finally, we look at whether either of the child's resident parents smoked when the child was aged nine months. Smoking rates were much lower for the continuously married group than for all other groups (29.6 per cent). Cohabitees who became lone parents and lone parents who went on to cohabit had the highest rates of parental smoking (65.8 per cent and 64.5 per cent respectively).

\section{Conclusions}

The experiences of the children in the MCS dataset show that, even in early life, there is evidence of a complex and dynamic pattern of family structures in which some children live. This article has shown a variety of typologies of family change over the first five years of life. About 20 per cent of the sample was made up of groups who experienced one change in family structure, while 7.5 per cent of children experienced more than one change in family structure in their first five years of life. Children born to lone parents were the most likely to experience a change in family structure by age five, with just under half of these children experiencing at least one change.

These findings show that the experience of family life of today's children is becoming more complex than those of earlier generations. For example, around 90 per cent of British Cohort Study children born in 1970 were still living with their parents by the time they turned five (Kiernan, 2004), compared with just under 75 per cent for the children in the MCS.

While these patterns highlight growing diversity and complexity in the living arrangements of today's young children compared with previous generations, our data also show that there is continued stability in certain groups. Three-quarters of all children did not experience any changes at all over the first five years of life. Over 90 per cent of children born to married parents and over 80 per cent of those born to cohabiting parents were still living with two parents by age five. In fact, during the first five years of their child's life, cohabitees were more likely to marry each other than to separate.

To describe the various typologies of family change, we looked at a number of social, economic and wellbeing indicators. Continuously married families were the most advantaged households. They had the highest incomes, were least likely to be in a routine occupation or not hold educational qualifications, had higher birthweight babies, were least likely to experience maternal depression or to include a parent who smokes. The most disadvantaged group across these domains was families who remained lone parents throughout the five years. A longitudinal indicator of poverty shows how persistent their economic disadvantage was: nearly 60 per cent of lone parent households were classed as poor across the three sweeps of data, and an additional 30 per cent had experienced poverty at least once. This confirms work done on older children by Clarke and Joshi (2003) who used data from the ONS Longitudinal Study to show that experiencing family instability was associated with subsequent economic disadvantage among children aged 5-17.

This article also highlights diversity across the groups which experienced family changes. Looking at socio-economic characteristics among those who experienced at least one change, cohabitees who later married appear to be the most economically advantaged, doing better than continuing 
cohabiting parents across a range of indicators although not as well as the continuously married. This confirms that cohabitants appear to be more economically disadvantaged than married couples (Kiernan and Estaugh, 1993). Married and cohabiting parents who separated during the five years were showing signs of economic disadvantage at nine months compared with their partnered peers. These two groups also lost the most income over the five years studied. Lone parents who later partnered had higher incomes than their continuously lone parent counterparts; however, they were still much more disadvantaged than the continuously partnered groups in spite of gaining the most income over the five-year study period.

These patterns are repeated across other socio-economic factors, such as occupational class and educational qualifications, as well as markers of health and wellbeing such as birthweight and maternal depression. Mothers who were continuously partnered had lower rates of depression at nine months than those who were continuously lone parents or who experienced periods of lone parenthood. This may be important in terms of child outcomes as maternal depression is linked with less effective parenting and poorer cognitive and emotional outcomes for children (Conger et al, 1992). Birthweight is an important marker of maternal stress and behaviours during pregnancy (Cnattingius, 2004), as well as being an indicator of later life health (Black et al, 2007; Harder et al, 2007; Barker, 1995). We show that married parents had babies with the highest birth weight, followed by cohabitees who later marry. The lowest birthweight was found among continuously lone parents and coupled parents who later separated, indicating perhaps that negative outcomes can be seen before separation occurs. Similarly, high rates of maternal depression among coupled parents who went on to separate were already observed when the baby was nine months old, before most relationship breakdowns had occurred.

There are some limitations to this work. A central issue to consider is that of causality. This descriptive paper highlights the circumstances of households that experience changes in family structure, however, we cannot comment on the direction of these associations. For example, poverty could be a result of experiencing family instability, but could also be the cause of such instability. The literature points to the difficulty of disentangling the issue of causality. Longitudinal analysis of the British Household Panel Survey by Jenkins (2008) shows that marital separation is associated with substantial splits in income shortly after separation and that while incomes do recover, they do not go back to pre-separation levels. However, analysis of the same data found that economically disadvantaged groups were more likely to subsequently divorce (Kiernan and Mueller, 1998; Clarke and Berrington, 1999). Similarly, stress (as expressed by maternal depression, parental smoking and having a low birthweight baby) is likely to both precede and follow parental separation (Booth and Amato, 1991). Conceptualising separation and re-partnering as a process rather than an event also means that the negative or positive consequences that can be observed before the actual separation or moving in of a new partner may not be the cause of the change in family structure but a by-product of the process that leads to the outcome, thus making it difficult to assess causality.

We did not look at when these changes occur, so we have not identified significant periods, other than noting that most of the changes in family structure appear to occur between nine months and three years. As for all cohort studies, some households did not participate in all sweeps. This can be a source of bias as these households are likely to be systematically different from the rest of the sample. For example, households who participate in sweep 1 but not in sweep 2 were more likely to come from a disadvantaged occupational class, to be lone parents and slightly less likely to 
speak English than those retained in sweep 2. The MCS, however, does try to recover households lost in one sweep for the next sweep, and 1,444 households that were not interviewed at sweep 2 were recovered at sweep 3 (Hansen 2008). Unit non-response (missing answers to certain questions) may also be a source of bias. For example, information on income was more likely to be missed for non-White ethnic groups (nearly a third of Bangladeshi households did not report their income compared with six per cent in the White group).

These analyses have some important strengths. The longitudinal nature of the data allows us to capture the diverse and changing family environments in which children live. As the MCS is a large and nationally representative study, the results do not only apply to selected groups, but can be generalised to the whole population.

In conclusion, these findings highlight the complexity and dynamic nature of family structures experienced by children over the first five years of life. We suggest that using static measures of family structures can hide important variations in the experiences of children. Alongside this diversity, we also recognise the stability of certain groups, and that children who experience changes in family structure in early childhood are a minority compared with those who remain in stable households.

\section{Acknowledgments}

Thanks go to the three anonymous peer-reviewers for helpful comments made on this article. We would like to thank the Millennium Cohort Study families for their time and cooperation, as well as the Millennium Cohort Study team at the Institute of Education. The Millennium Cohort Study is funded by ESRC grants to Professor Heather Joshi (study director). This work is funded through support from the Economic and Social Research Council and the Medical Research Councils.

\section{Notes and References}

1 The ethnic minority indicator is based on 1991 Census data as it is the only data available at ward level. The categories 'Black' and 'Asian' were defined as:

a) 'Black': Black Caribbean, Black African and Black Other as reported on the Census form;

b) 'Asian': Indian, Pakistani and Bangladeshi as reported on the Census form.

2 The income measure presented in this article are 'equivalised' to take account of different family sizes and compositions. Equivalised income is calculated using McClements equivalence scale. This measure does not take account of the detailed child weights in the McClements scale. Instead, all dependent children in the household are assigned the average of the child weights of 0.23 .

3 Parental occupations are classed according to the National Statistics Socio-Economic Classification (NS SEC) in all official statistics. These socio-economic classifications are based on occupation, in combination with employment status and in some circumstances 
size of workplace. The lowest occupational categories include jobs classed as routine and semi-routine occupations, which are presented in this article.

Aassve, A, Betti, G, Mazzuco, S and Mencarini, L (2007) 'Marital disruption and economic wellbeing: a comparative analysis'. Journal of the Royal Statistical Society 170(3): 781-799.

Amato, PR (2001) 'Children of divorce in the 1990s: An update of the Amato and Keith (1991) meta-analysis'. Journal of Family Psychology 15: 355-370.

Amato, PR (2005) 'The Impact of Family Formation Change on the Cognitive, Social, and Emotional Well-Being of the Next Generation.' The Future of Children 15(2): 75-92.

Amato, P. R. and Keith, B. (1991) 'Parental divorce and adult well-being: A meta-analysis'. Journal of Marriage and Family 53(1): 43-58.

Aquilino, WS (1996) 'The life course of children born to unmarried mothers: Childhood living arrangements and young adult outcomes'. Journal of Marriage and the Family 58(2): 7.

Barrett, AE (2000) 'Marital Trajectories and Mental Health'. Journal of Health and Social Behaviour 41 (4), 451-464.

Barker, DJP (1995) ‘Fetal origins of coronary heart disease'. British Medical Journal 311(6998): 171.

Black, SE, Devereux, PJ et al. (2007) 'From the Cradle to the Labor Market? The Effect of Birth Weight on Adult Outcomes'. The Quarterly Journal of Economics 122(1): 409-439.

Booth, A. and Amato, P. (1991) Divorce and psychological stress. Journal of Health and Social Behavior, 32, 396-407.

Brown, SL (2004) 'Family Structure and Child Well-Being: The Significance of Parental Cohabitation'. Journal of Marriage and Family 66(2): 16.

Cherlin, AJ, Chase-Lansdale, PL et al. (1998) 'Effects of parental divorce on mental health throughout the life course'. American Sociological Review 63(2): 239-249.

Clarke, L and Joshi, H (2003) Children's changing families and family resources. In Jensen, AM and McKee, $\mathrm{L}$ (eds) Children and the Changing Family: between transformation and negotiation. London: RoutledgeFalmer.

Clarke L and Berrington, A (1999) 'Socio-demographic predictors of divorce'. Published in: Simons $\mathrm{J}$ (ed.) High divorce rates: The state of the evidence on reasons and remedies: Reviews of the evidence on the causes of marital breakdown and the effectiveness of policies and services intended to reduce its incidence. Lord Chancellor's Department Research Series, 1 2/99, London. 
Cnattingius, S (2004) 'The epidemiology of smoking during pregnancy: smoking prevalence, maternal characteristics, and pregnancy outcomes' Nicotine \& Tobacco Research 6 (Supplement 2): S125.

Conger, R D, Conger, KJ et al. (1992) 'A family process model of economic hardship and adjustment of early adolescent boys'. Child Development 63(3): 526-541.

Dex, S and Joshi, H (2005) Children of the 21st century: from birth to nine months. The UK Millennium Cohort Series. Bristol, Policy Press.

Hansen, K. Ed. (2008) The Millennium Cohort Study: A Guide to the Datasets, 3rd Edition. London, Centre for Longitudinal Studies, Institute of Education.

Harder, T, Rodekamp, E et al. (2007) 'Birth weight and subsequent risk of type 2 diabetes: a metaanalysis'. American journal of epidemiology 165(8): 849.

Jenkins, J (2008) Marital splits and income changes over the longer term. ISER Working Papers WP2007-2008.

Kiernan, K (2004) 'Cohabitation and Divorce across Nations and Generations'. In Chase-Lansdale, PL, Kiernan, K. and Friedman, R.(eds) Human Development Across Lives and Generations. Cambridge, Cambridge University Press.

Kiernan, K (1997) The Legacy of Parental Divorce: Social, economic and demographic experiences in adulthood. CASEpaper 001.

Kiernan, K. and Estaugh, V. (1993) Cohabitation Extra-marital Childbearing and Social Policy. Joseph Rowntree Foundation/Family Policy Studies Centre.

Kiernan, K and Mueller, G (1998) The divorced and who divorces? CASEpaper 7. Centre for Analysis of Social Exclusion, LSE, London.

Office for National Statistics (2001) Birth statistics 2000, series FM1 no 29. Available at: www.statistics.gov.uk/StatBase/Product.asp?vlnk=5768\&Pos=\&CoIRank=1\&Rank=224

Plewis, I, Ed. (2007) The Millennium Cohort Study: Technical Report on Sampling, 4th edition. London, Centre for Longitudinal Studies, Institute of Education.

Richards, M, Hardy, R and Wadsworth, M (1997) 'The Effects of Divorce and Separation on Mental Health in a National UK Birth Cohort'. Psychological Medicine 27 (5), 1,121-1,128.

Rutter, M., J. Tizard and K. Whitmore (1970) Education, Health and Behaviour. London: Longman. 